NASA/TM- $/ G \% \dot{E}-208121$

\title{
BUCKLING ANALYSIS OF ANISOTROPIC CURVED PANELS AND SHELLS WITH VARIABLE CURVATURE
}

\author{
Navin Jaunky and Norman F. Knight, Jr. \\ Old Dominion University \\ Norfolk, VA 23529-0247
}

\author{
Damodar R. Ambur \\ NASA Langley Research Center \\ Hampton, VA 23681-0001
}

Presented at the 39th AIAA/ASME/ASCE/AHS/ASC

Structures, Structural Dymanics, and Material Conference

AIAA Paper 98-1772

Long Beach, California

April 20-23, 1998 


\title{
BUCKLING ANALYSIS ()F ANIS()TROPIC CURVED PANEL' AND SHELLS WITH VARIABLI C'RVATLRE
}

\author{
Navin .Jaunky* and Noman F. Kinight, .Jr. ${ }^{\dagger}$ \\ Old I)ominion (toiversity \\ Norfolk. VA $23529-0247$ \\ Damodar R. Ambur ${ }^{\ddagger}$ \\ NASA Langley hesearcli (enter \\ Hampton, VA 23681-0001
}

\begin{abstract}
A buckling formulation for anisonropic curved panels with variable curvature is presented in this pajer. The variable curvature panel is assumed to consists of two or more panels of constant but different curvatures. Bezier functions are used as Ritz functions. Displacement. ((") $)$, and slope ((!) contimuities betwen segments are imposed by manipulation of the Bezier control points. A first-orter shear-deformation theory is used in the buckling formulation. Results obtained from the present formulation are compared with those from finite element simulations and are found to be in good agreement.

\section{Nomenclature}

\begin{tabular}{|c|c|}
\hline $0, v_{0}$ & $\begin{array}{l}\text { cement along ax } \\
\text { cerse directions }\end{array}$ \\
\hline i: & ne'nt along radial \\
\hline$\phi_{u}$ & $\begin{array}{l}\text { is of normals to } \\
\text { surface or curvatures }\end{array}$ \\
\hline$, y, 2$ & $\begin{array}{l}\text { axial, circumferential, and } \\
\text { normal coordinates }\end{array}$ \\
\hline il & Bezier polynomial of order \\
\hline & Bezier control points \\
\hline
\end{tabular}
\end{abstract}

*Posidoctoral Research Associate, Department of Aerospace Enginereing. Menber AlA

tProfessor, I pepartment of Aerospare Engineering. Associate Fellow ALAA.

†ssistant Hearl, Structural Mechanies Brandh. Assuviatf Fellow AIAA.

${ }^{1}$ Copyright (O) 1948 by Navin Jaunky. Published by A IAA with permission.
$\{, \eta$ non-dimensional coordinates

$l$ length of segment

Si widtl of segnent I

$l$ Radius of curvature

\section{Introduction}

The use of composite materials for aircraft mrimary structures can result in significant benfits on aircraft performance and structural cost. Guch applications of composite materials are expected to result in a $30-40$ percent weight savings and a 10-30 percent cost reduction compared to conventional metallic structures. Shells with variahle curvature are widely used for aircraft fuselage and wing components. The variahle curvature configuration for these structures is due to aerodynamic and functional considerations. Hence the understanding of buckling beshavior of composite shells with variable curvature is of importance for aerospace structural design.

The earliest work reported on the buckling analysis of shells with variable curvature was by Marguere [1] in 1951. He expanded the curvature in a fourier series with respect to the circumferential arc-length in order to nore accurately represent the varying curvature of wing leading edge panels. His approach has been the basis for subsequent analyses of shenlls with rarying curvature for both buckling $([2]-[4])$ and vibration problems ([5]-[11]). In these References Marguerre's approach has been used for elliptical cylinders or panels since the variation of curvature $(1 / R)$ can be represented accurately by one term in the Fourier series. Reference [4] provides 
an excellent review for buckling and vil ration of shells and panels with variable curvatue.

In addition to elliptical cylinders or panels. shells with varying curvature such as isotropic conical ([12, 1:3]) and torispherical shells ([1:3]) have been analyzed for free vibration lrie ef al. [12] used the transfer matrix techniques to obtain natural frequencies of truncatel conical shells. According to Reference [12], the advantage of the transfer matrix technique is its simplicity compared to other methods which require considerable analytical effort and computational time. A review of the literature for concal shell shell buckling is provided in Reference [12]. Singh ([1:3] used a segment approach where a series of circular arc segments tangential to each other at the segutent interface juncture jis used to model the shell with varying curvature (e.g., conical and torispherical shell) without any approyination in geometry. Trigonometric and quinti. Bezier polynomials are tsed to represent displacement fickls in rach are segment. Smooth dinformed surface of the shell are obtained by imposing (") and (" continuties at the juncture of 1wo adjacent shell segutents by using the properties of the Bozier control points. Also boundary conditions are applied by simple manipulation of the Bezier control points. Bezier polynomials have heen used in a segment approach for the free voration of isotropic elliptic cylinders ([14]), composite elliptic cylimders ([15, 16]), and a laminated conical shell ([16]). A first-onder shear-deformation 1.heory has been used in References [15] and [16]. Detailed reviews of the free vibration of sholls with variable curvature are discussed in References [1:3]-[16]. The method presented in Refcrences [1:3]-[16] can be applied to different shell geometries, shells with anisot ropic material properties, and shells with arbitrary boundary conditions. In addition. the nethod ran incolporate first-order shear-deformation theory or chassical laminated plate theory and is computationally efficient.

The present analysis method for buchling of anisotropic shells with variable curvature uses a segment approach where displacement fields within each segment are represented by Bezier polynomials and a first-order shear-deformation theory is used. In general, segments can be used in both axial and circumferential directions, however the present implementation considers only segments in the circumferential direction. Contimuity of displacement at the junctures of aclacent segments are imposed using (") and (" conditions oblained from the properties of the Bezier control points $([14])$. The sleell with variable curvature is assumed to consist of two or more curved panels of constant curvature which is representative of fuselage or wing structures.

The present paper summarizes the analysis approach. Two structure cases with curvature are analyzed to demonstrate the capabilities of the present analysis approach. Result from the present andysis are compared with those oltained from finite element analyses.

\section{Analytical Approach}

'Tle coordinate system and the displacement. directions for a noncircular shell is shown in Figure 1. Any point in the wall of the shell is specified by means of curvilinear coordinate system $x$. $y$ and $z$, where $t$ is the axial coordinate fixed to mid-surface, $y$ is the circumferential coordinate which follows the median line of the transwerse cross section, and $z$ is the radial coordinate normal to both $x^{x}$ and $y$. The noncircular shell is assumed to consist of two or more segments in the' circumferential direction each of constant radius. The normal and tangent of the two segments at a juncture are equal as shown in Figure l, where $\vec{n}_{1}=\vec{n}_{2}$ and $\vec{t}_{1}=\vec{t}_{2}$.

Bezier polynomials are used in the axial and circumferential directions to represent the displacement fields. The Bezier polynomial is given by

$$
f_{i}(n, \nu)=\frac{n !}{(i-1) !(n-i+1) !} \nu^{i-1}(\nu-1)^{n-i+1}
$$

where $n$ denotes the order of the polynomial and $0 \leq \nu \leq 1$. For a Bezier polynomial of order $n$. there are $(n+1)$ control points. Any point on the surface of the segment is given by a parametric function of the form

$$
P_{r s}(\xi, \eta)=\sum_{r=1}^{\lambda} \sum_{s=1}^{Y} f_{r}(\xi) f_{s}(\eta) q_{r s}
$$

where the coordinates $\xi$ and $1 /$ are defined as

$$
\begin{aligned}
& \xi=x / L \\
& \eta=\left(y-y_{i}\right) /\left(y_{i+1}-y_{i}\right)
\end{aligned}
$$

with $0 \leq \xi . \eta \leq 1, X$ and $Y$ are the number of control points in the axial and circumferential direction respectively, and $q_{r s}$ are the Bezier control points or coefficients. 'The displacenent vector can loe written as 
by

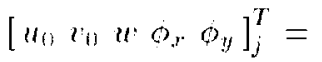

$$
\begin{aligned}
& {\left[\begin{array}{ccccc}
P_{r s} & 0 & 0 & 0 & 0 \\
0 & P_{r, s} & 0 & 0 & 0 \\
0 & 0 & P_{r, s} & 0 & 0 \\
0 & 0 & 0 & P_{r, s} & 0 \\
0 & 0 & 0 & 0 & P_{r, s}
\end{array}\right]_{j}\left\{\begin{array}{l}
q_{1} r s \\
q_{2, s} \\
q_{3 r, s} \\
q_{4, r s} \\
q_{5, r s}
\end{array}\right\}_{j}}
\end{aligned}
$$

where $u_{0}$ and $v_{0}$ are the axial and transverse membrane displacements. respectively. $w$ is the normal disphacement and $\phi_{y}$ and $\phi_{y}$ are the curvatures. Subscript $j=1,2,3 . \ldots\left(X Y^{\circ}\right)$. "The control points for each degree of freedom can be usere to impose bomudary conditions on each degree of freestom on each segunent.

Continuity of diaplacement functions along segment junctures are dobained loy using the relations between control points of the adjacent seegnenent hased on (" and (" continuities. Figure 2 shows two adjatend semenents and the control points that are incolved in the (") and (") $^{\circ} \mathrm{con}^{-}$ tinuities for the case of elevell control points in the axial clirection and sis control points in the transverse direetions. $i$. . . $Y=11$ and $Y=6$. In the $I^{\text {th }}$ segrinent, cont rol points $q k$ ti and qk:5 are res lated to control points $q_{1}$ a and $q_{i 2}$ of the $(I+1)^{\text {th }}$ segment, where $i . k=1,2.3 .4 .5,6$ according to

$$
\begin{aligned}
& q_{i j k}=q_{1} \\
& \psi_{1 ; k}=\frac{\dot{r}_{1} q_{j k}+\dot{s}_{1+1} q_{2 i}}{\dot{y}_{1}+\dot{r}_{1+1}}
\end{aligned}
$$

where $s_{1}$ and $s_{1+1}$ are the width of the $I^{\text {th }}$ and $(I+1)^{t h}$ segment respeclively. Ising these conditions the unk nowns q1; and qua are expressed in terms of 45 and quik. Which are slaved to the master cout rol points $q_{1}$, and q $q_{2,}$.

Since the buckling andysis involves firstorder shear-deformation, only (") continuity is required in the mriational formulation. However the advantage of also imposing (" continuity is not only to obtain a more accurate analysis but also to reduce the size of the stiffiness and geesmetric stiffness matrices when a larger number of segments are used to represent the shell that is being analyzed. Table I shows the size of the matrices with the number of segments for different conditions of continuities when $X=11$ and $Y=6$. If the segments are joined to approximate a shell, the size of the matrices are less than that for a panel. The size of the stiffness and geometric stiffiness matrices after assembly is given

$$
\begin{gathered}
\text { ISIZE }= \\
5 \times \mathrm{X} \times \mathrm{Y} \times \mathrm{NSLO}-110 \times \mathrm{MNOIN}
\end{gathered}
$$

for (") and (" continuities, where ls'tZE is the matrix size. NSEC is the number of segments, and MJOIN $=$ NSEC -1 for a panel and MJOIN = NSEg for a shell, i.e. MJOIN is the mumber of junctures.

The linear stiffuess matrices are derived from the strain energy which is given by

$$
V=\frac{1}{2} \int_{A}\{c\}^{T}\left[\begin{array}{ccc}
A_{i j} & B_{i j} & 0 \\
B_{i j} & D_{i j} & 0 \\
0 & 0 & C_{r q}
\end{array}\right]\{c\} d A
$$

where $A_{i j}$ is the extensional stiffuess coefficient matrix. $B_{i j}$ is the coupling stiffuess coeflicient matrix. $D_{i j}$ is the bending stiffuess coeflicient matrix and $C_{p}$ is the transverse shear stiffuess coefficient matrix. The strain vector is $\{c\}$ and

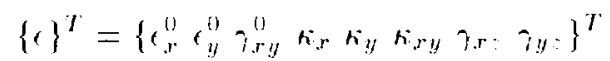

The strain displacememt relations are

$$
\begin{aligned}
& f^{\prime \prime}=\frac{\partial u_{0}}{\partial x} \\
& c_{y}^{\prime \prime}=\frac{\partial v_{0}}{\partial y}+\frac{\omega_{0}}{R} \\
& i_{x y}^{\prime \prime}=\frac{\partial u_{0}}{\partial y}+\frac{\partial r_{0}}{\partial x} \\
& r_{. r}=\frac{\partial \phi_{r}}{\partial, r} \\
& \kappa_{y}=\frac{\partial \phi_{y}}{\partial y} \\
& \kappa_{r y}=\frac{\partial \phi_{r}}{\partial y}+\frac{\partial \phi_{y}}{\partial \partial_{r}}+\frac{(\dot{\partial}}{2 R}\left(\frac{\partial \varphi_{u}}{\partial x}-\frac{\partial u_{0}}{\partial y}\right) \\
& i_{r}^{\prime \prime}=\partial_{r}+\frac{\left.\partial u_{0}\right)}{\partial \partial_{x}} \\
& i_{y}^{\prime \prime}=\phi_{y}+\frac{\partial u_{(1)}}{\partial y}-\sigma_{1} \frac{v_{0}}{R}
\end{aligned}
$$

Ilere $\left(C_{1}\right.$ and $(\therefore$ are "tracer" coefficients used to implement different strain-displacement relations or shell theories. Accordingly when $C_{1}=C_{2}=$ 1. the first approximation of Sanders- hoiter shell theory $[1 \bar{T}, 18]$ is obtained and when $\left(C_{1}=1,(2\right.$, $=0$. Love's shell theory [19] including transwerse shear deformations is obtained. Finally. when $\left(_{1}\right.$ $=0$ and $\left(\vdots_{2}=0\right.$, Donnell's shell theory [20] including transverse shear deformation is ohtained. 
The geometric stiffuess matrix is derivel from the work done, $\left(H_{d}\right)$. by the applied prebuckling londing and is

$$
\begin{aligned}
H_{i l}= & \int_{A}\left(\overline { N } _ { x } \left(x N L+\bar{N}_{y+y N L}\right.\right. \\
& \left.+\bar{N}_{x y \text { PyNL }}\right) d A
\end{aligned}
$$

where the nonlinear strain components are

$$
\begin{aligned}
& \left(i_{r}\right) x_{L}=\frac{1}{2}\left(v_{0}, \frac{2}{n}+u, \frac{2}{r}\right) \\
& \left(c_{y}\right)_{N L}=\frac{1}{2}\left(u_{0} \cdot \frac{2}{y}+\left(w^{\prime} \cdot y-\frac{v_{1}}{R}\right)^{\frac{\cdot}{2}}\right)
\end{aligned}
$$

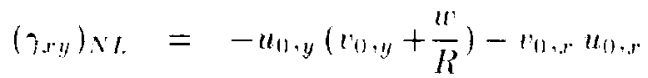

$$
\begin{aligned}
& +u,, r\left(u, y-\frac{v u}{R}\right)
\end{aligned}
$$

In the present analysis the applied prebuckling loading is prescribed as a uniform in-plane steress state. The linear stiffiness and geometric stiffuess matrices are developed using analytical integration rather than numerical integration for computational efliciency. Finally, an eigenvalut problem is solved for determining the critical buckling load.

\section{Numerical Results}

Results are presented for a composite cylindrical panel subjected axial compression and a composite wing leading-edge panel subjected to combined axial compression and shear. SandersKoiter $([17,18])$ shell theory is used in these studies. Buckling loads from the present analysis are compared with those olutained from the STA(iS ([21]) linite benent cole. The STACis finite clement model consists of the 410 elenent and curved surfaces are approximated as an assembly of flat surfaces. 'The nominal ply mechanical properties for the composite material used are:

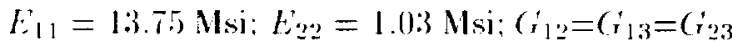
$=0.420 \mathrm{M}$ si and $\nu_{12}=0.250$, and the laminate ply stacking sepuence is $[ \pm 45 / 0 / 90 / \pm 45]$, with rqual ply thickness for different laminate thickness.

\section{( ylindrical Panel}

The first structure analyzed is a semicircular $\left(a=18()^{\circ}\right)$ cylindrical panel 22.(0-in. long, and with a radius of 40.0 inches. as shown in Figure :3. The simply-support boundary conditions are also shown in Figure 3. 'The cylindrical panel is modeled as five curved segments in the present analysis while the STACS finite olement modeled consists of 20 and 40 elenents in the axial and transverse direction respectively. Table 2 shows the results for the curved panel subjected to axial compression load.

The results in Table 2 suggest that for $t=$ $0.072 \mathrm{in}$. the present analysis result is 4.3 percent greater than the S'TA(is result while for $t$ $=0.144 \mathrm{in}$. and $0.216 \mathrm{in}$. the STA is analysis results is 1.4 percent helow that of the present analysis. The difference between results is due to using the 410 shell element of STAGs which do not include transverse shear deformation. The STACiS results are above that of the present anal$y$ sis for $t=0.144 \mathrm{in}$. and $0.216 \mathrm{in}$. since these two panels are thicker and transverse shear deformation effects are significant. The buckling mode shape for the curved panel obtained from STACiS analysis results is shown in Figure 4.

Wing Leading-Edge Panel

The wing leading-edge panel is shown in Fig'ure 5. It consists of three curved segments of radii $50.0 \mathrm{in.}, 6.130 \mathrm{in.}$, and $50.0 \mathrm{in.}$, respectively. The boundary conditions of the panel is shown in Figure 5 and correspond to classical simply support conditions. Fach ply of the laminate is 0.006 -in. thick. Ising the present analysis, the wing leading edge was modeled as combination of two segments for the 50.0 -in. radius section and one segment for the 6.130 in-in. radius sertion. The STARiS finite element model consists of the 410 shell element and $30 \times 30$ elements in each curved segment, and the formulation of the 410 element is hased on the classical haminated plate theory. 'Table 2 shows the results obtained from the present analysis and those from STACiS for some selected combined load cases and Figure (j) shows the buckling load interaction curve between axial compression and positive shear loading.

The resules from the present analyses are about 4.0 percent above those of Slicis except for the case of negative slear loading where the result from the present analysis is 6.4 percent above that of STACis. Bottor agreement can be obtained from the present method by using more control points in the axial direction. However this will lead to more computational effort and the present percentage difference between STAGS and results from the present analyses is considered acceptable for a preliminary design. The buckling mode shape for the wing leading 
edgo ohtained from SIA is analysis results are shown in Figure 7,8 and 9 for axial compression. and positive and negalive shear, respecelively. The shell deformation is mostly in the 50.(1-int radius curved segunents. For the case of positiw slear. the shell deformation is mostly in olle of the iolo-in. radius curved segment.

\section{Concluding Remarks}

1 formulation lats been developerl for bucklime of anisotropic laminated slecls with variable itrualute. The variable curvature is approsimbited by two or more segment of constant foul dillienell curvatures. Bezier polynomials are Ine a Rity functions in the structural axial and

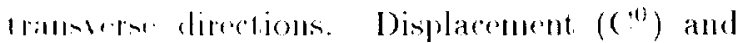

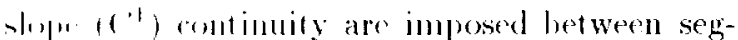
III. III- Liesults olutained from the formulation irr valinlated using finter element simmations. Burkling luakls obtained from finite element solution are tefermined to be four pereent lower llath l lane al the present analysis.

\section{Acknowledgement}

1 lo wurk of the first two aubors was sup-

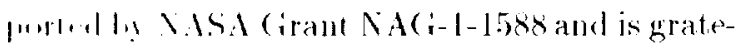
lull interewledged.

\section{References}

1] K. Watrenerre, "Stability of the Cylindri"al Shell of Variable curvature," NASA TM 1:3112. 10.51.

[:] 1 \%"l. Y. N., and kempmer J., "Large bullerion of an Axially (ompressed Oval c ylumbical Shell," Proceseding of $)^{\text {th }}$ Interllalional congress on Applied Mechanics." Munich, Gormany, 1961, Springer-Verlag, B.rliu. p). 299-305, 1965).

[:3] Slminman. I, and Frier. M., "Buckling Analsisin of Laminated cylindrical Shells with Aritrary Noncircular ( 'ross Section," AIAA lomrmal. Vol. 32. No.3, March l994, pp. 648dilil.

[1] ramol A. Meyers, "An Analytical and Experimontal Investigation of Elliptical (omposite (ylinders," Virginia Polytechanic Inslitur and State I niversity, Pl. IJ. dissertation in Finginerering Sicience and Mechanics, April 1996.
[5] Boyd, I). E.., "Analysis of Operll Non-circular cylindrical Slaells," AIAA Journal. Vol. T. No. 3, 1969, Pp. 56:3-565.

[6] Lurt, ( $\therefore$ F., and Boyd, D. E., "Frer Vibration of Non-circular (ylindrical Shell Siegments," ALAA Jommal, Vol. 9, No. 2. 1971. गए. $2339-244$.

[7] (ulberson, L. D), and Boyd. 1). E.. "Free Vibrations of Freely Supported Oval cylinders," AlAA Jonrmal, Vol. 9, No. \&. 1!Tl. Pp. $1474-1480$.

[8] Elsbermd, (i. F.. and Ierissa, A. W., "Th" Vibrations of Son-circular Shells with Initial Stresses," Journal of tound and Vibration. Vol. 29, No. 3, 197:3, p]). 309-329.

[9] Chen, Y. N., and Kempner, I.. "Modal Merhod for Free Vibration of Oval cylindrical Shells with Simply Supported or Clamped Ends." ASME Journal of Applicd Mechanics, Vol 45. No. 1, 1978. pp. 142-148.

[10] Konmousis, V. K. and Armenakas, A. E.. "Free Vibration of Non-circular Panels with Simply Supported c'urved Felges," As' Jourmal of tinginetring Herhanics, Vol. 110, No. 5, 1984, p). 810-827.

[11] Kommousis, V' K.. and Armenakas, A. L. "Free Vibration of Simply Supported cylindrical Shells," AlAA tournal. Vol. 21 . No. т, 198:3, ㄱ. 1017-1027.

[122] Irie, T., Yamada, (i., and Kanteko. Y.. "Fros Vihration of of a ('onical shell with Variable Thickness." Journal of tound and Libration. Vol. 82, No. 1. 1982, pp. 8:3-94

[1:3] Singl, A. V.. "On Vibrations of Shells of Revolution Ising Bezier Polynomials," AsME Jourmal of Pressure lessel Trchnology, Vol. 113, November 1991, pp. 579-584

[14] Kumbr, V., and Singh. A. V., "Vibration Analysis of Non-circular ( ylindrical Shells Itsing Bezier Functions," Journal of Stound and Vibration. Vol. 161, No. 2, 1993, pp. $3333-354$.

[15] Kimmar. V., and Singh. A. V., "Vibration of ('omposite Non-circular ('ylindrical Shells." AsME Journal of Vibration and Acoustics. Vol. 117. October 1995, pp. 470-476. 
[16] Kumar, V., and Singh. A. V., "Vibration of Fiber-Reinfored Laminated Deep Shells," AsilE Jourmal of Pressure Vessel Terhnology. Vol. I18, November 1996, pp. 407-414.

[17] Sanders, J. I. Jr., "An Improved First Approximation Theory for Thin Shells," NASA Report R-24, 1959.

[18] Koiter, W. 'I'., "A ('onsistent First Approxination in General Theory of Thin Elastic Shells," The Theory of Thin Elastic Shells, Procerdings IITAM Symposium, Delft. 1959, рp. 12-333. 1960. Amsterdam, the Netherlands, Vorth-Holland Publishing (ompany.

[1!)] Love. A. F. H.. A Treatise on the Mathematical Theory of Elasticity, 4th edition, New York, Dover Publication, 1927.

[20] Loo, T. T., "An Extension of Domnell's Eepuation for (ircular (ylindrical Sileell." Journal of Acromatical icieneses. Vol. 24. 1957. PJ. 390-3991.

[21] Brogan, F. A. Rankin. ('. ('.. Cabiness, H. I)., and William, A. L., "STAG(is liser"s Mammal," Iockheed Martin Missiles of Space ('ompany Inc., Report LMMSc P(032594, Version 2.3. 19969.
Table 1 Size of stiffuess matrices for panel and shell for increasing number of segments.

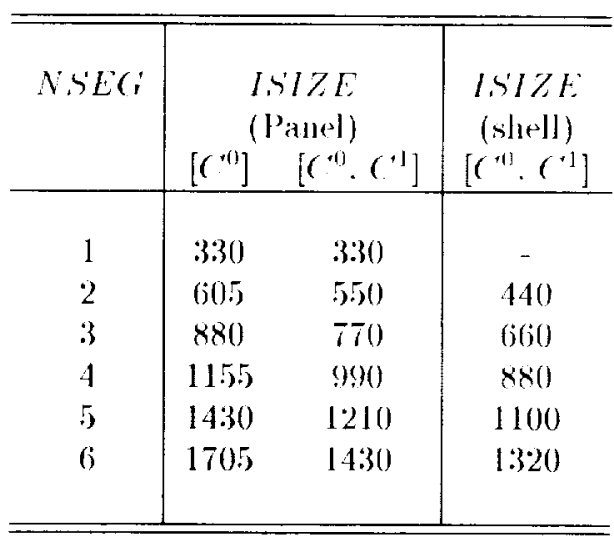

Table 2 Comparison of buckling loads results for composite curved panel.

\begin{tabular}{ccc}
\hline \hline $\begin{array}{c}\text { Thickness } \\
t \text { (in.) }\end{array}$ & STA(is & $\begin{array}{c}\text { Present } \\
\text { analysis } \\
\text { (Ilss/in.) }\end{array}$ \\
& & \\
& & \\
0.072 & $374.55)$ & 390.68 \\
0.144 & 1481.08 & 1459.45 \\
0.216 & 3328.25 & 3278.86 \\
\hline \hline
\end{tabular}

Table :3 comparison of buckling loads results for wing-leading edge pancl.

\begin{tabular}{|c|c|c|c|}
\hline \multicolumn{2}{|c|}{$\begin{array}{l}\text { Loading } \\
\text { condition }\end{array}$} & $\begin{array}{l}\text { STACiS } \\
\text { (lhs/in.) }\end{array}$ & $\begin{array}{l}\text { Present } \\
\text { allalysis } \\
\text { (1los/in.) }\end{array}$ \\
\hline 1.0 & 0.0 & 304.67 & $317.0: 3$ \\
\hline 1.0 & 0.4 & 194.48 & 202.57 \\
\hline 1.0 & 1.0 & 106.68 & 110.90 \\
\hline 0.4 & 1.0 & 124.39 & 129.53 \\
\hline 0.0 & 1.0 & -117.73 & -125.37 \\
\hline 0.0 & 1.0 & 139.31 & 145.555 \\
\hline
\end{tabular}




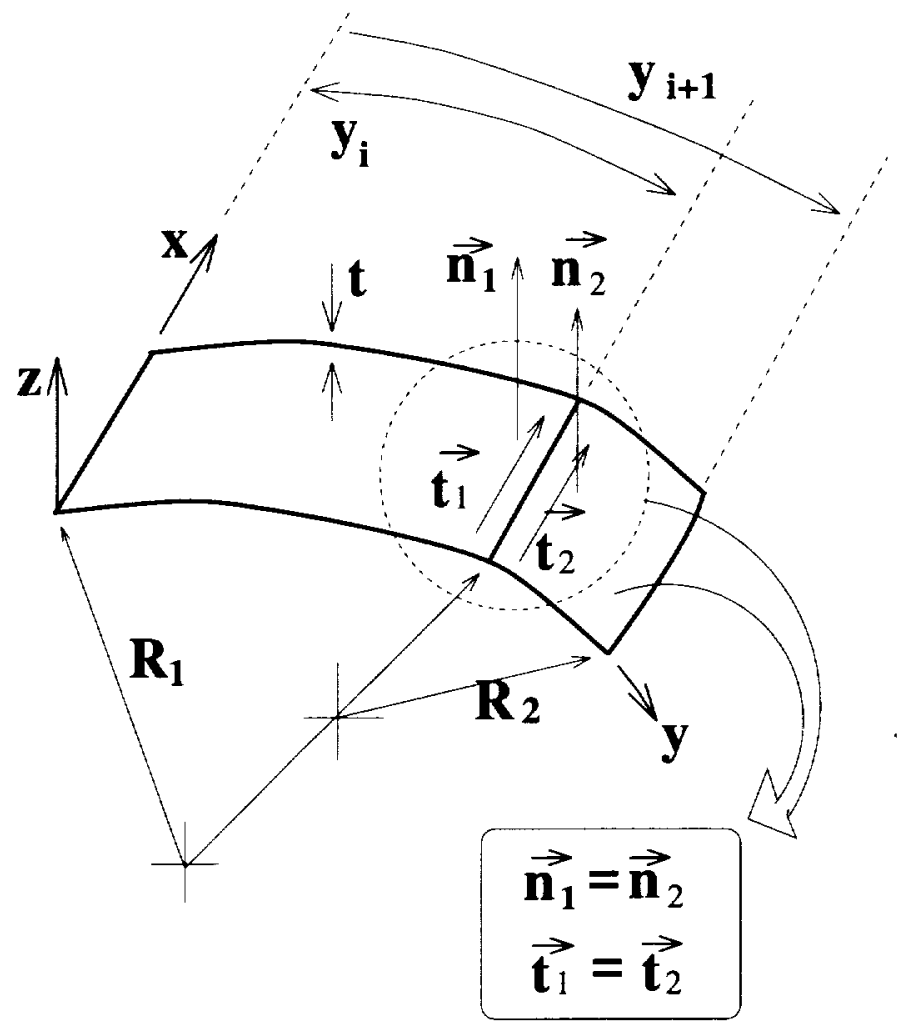

Figure 1: ('oordinate system and geometry of shell with variable curvature.

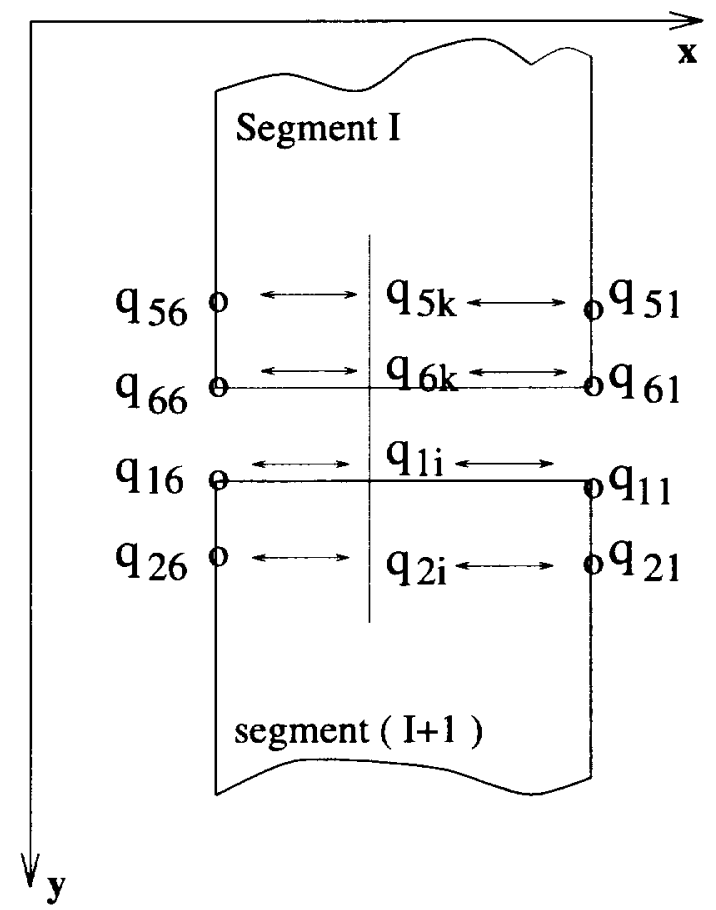

Figure 2: ('ontrol points for joining sheell segments. 


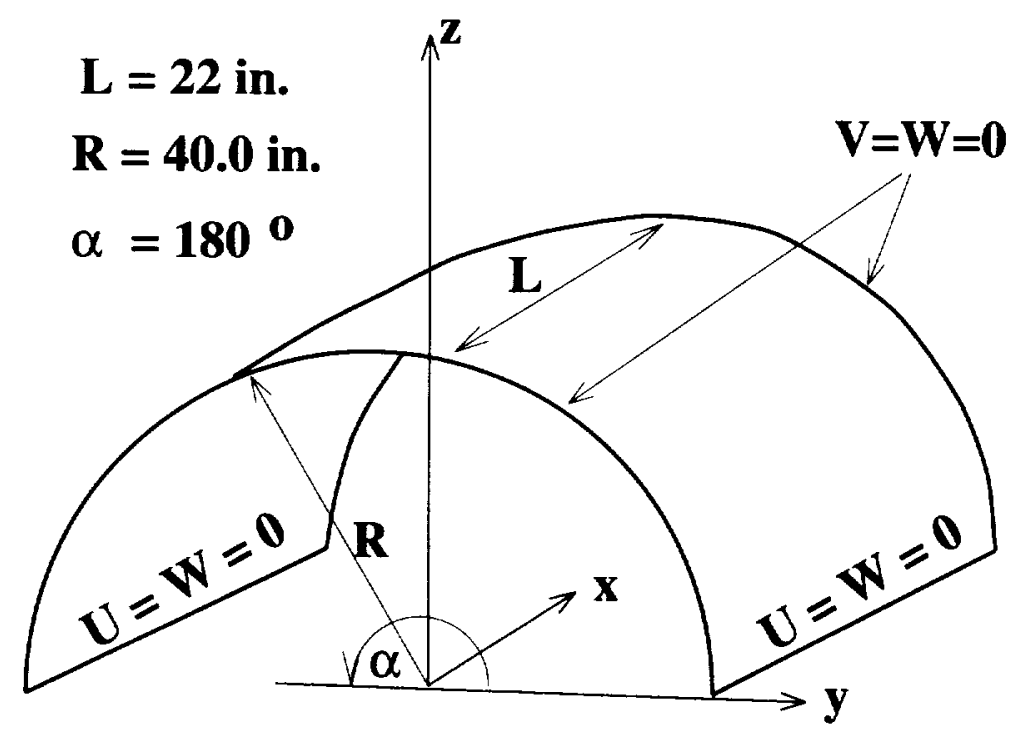

Figure 3: (ieometry and boundary conditions of curved composite panel.

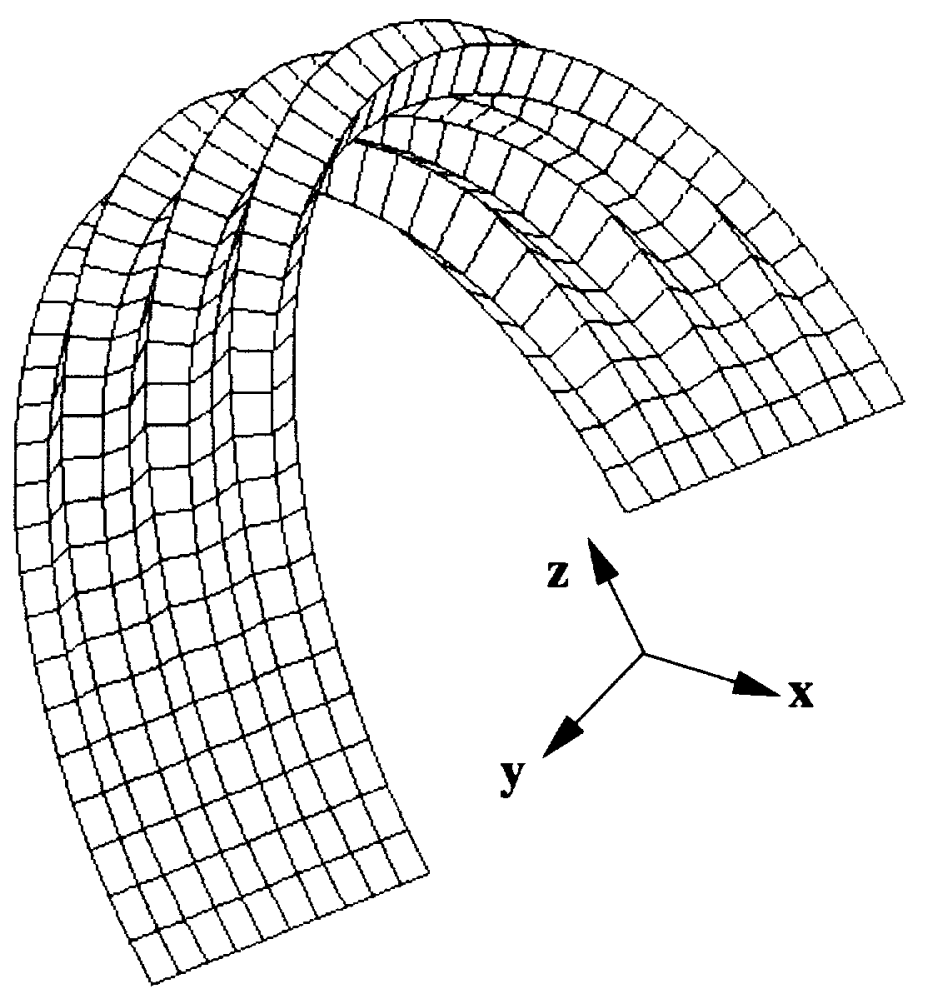

Figure 4: Buckling mode shape for curved composite panel. 


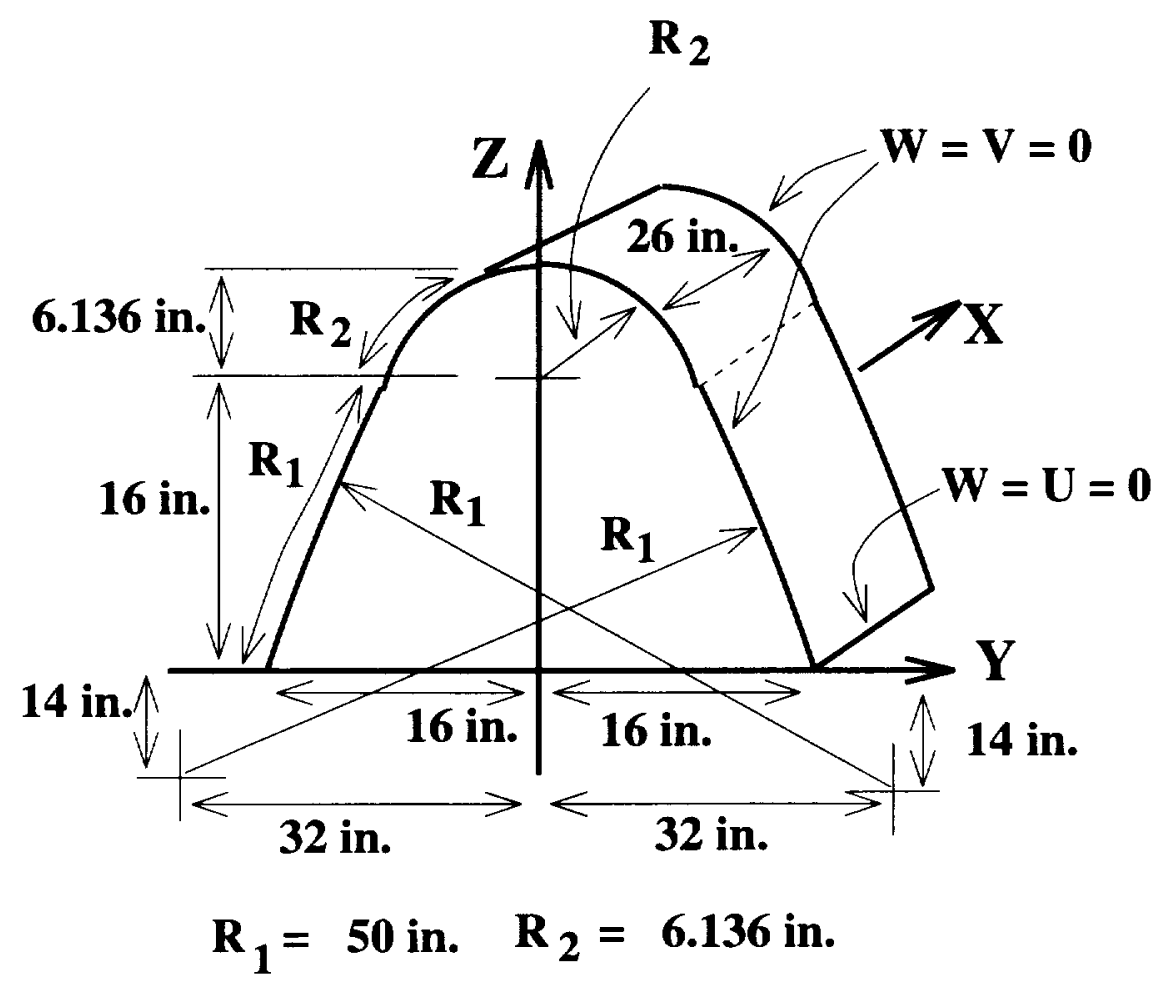

Figure 5: (irometry and dimensions of composite wing leading-edge panel.

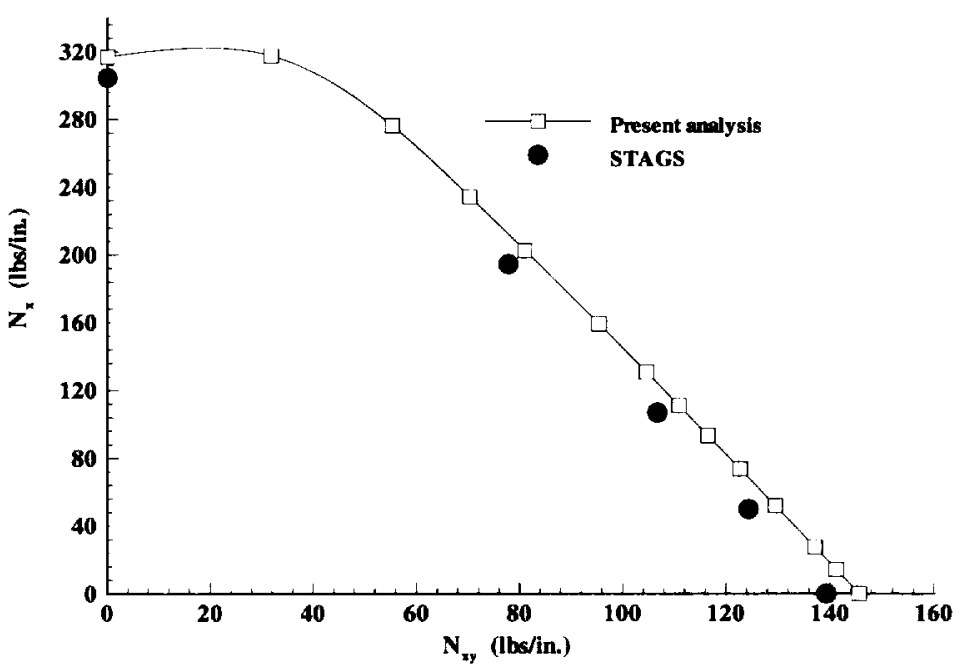

Figure 6: Buckling load interaction curve for the composite wing-leading edge panel 


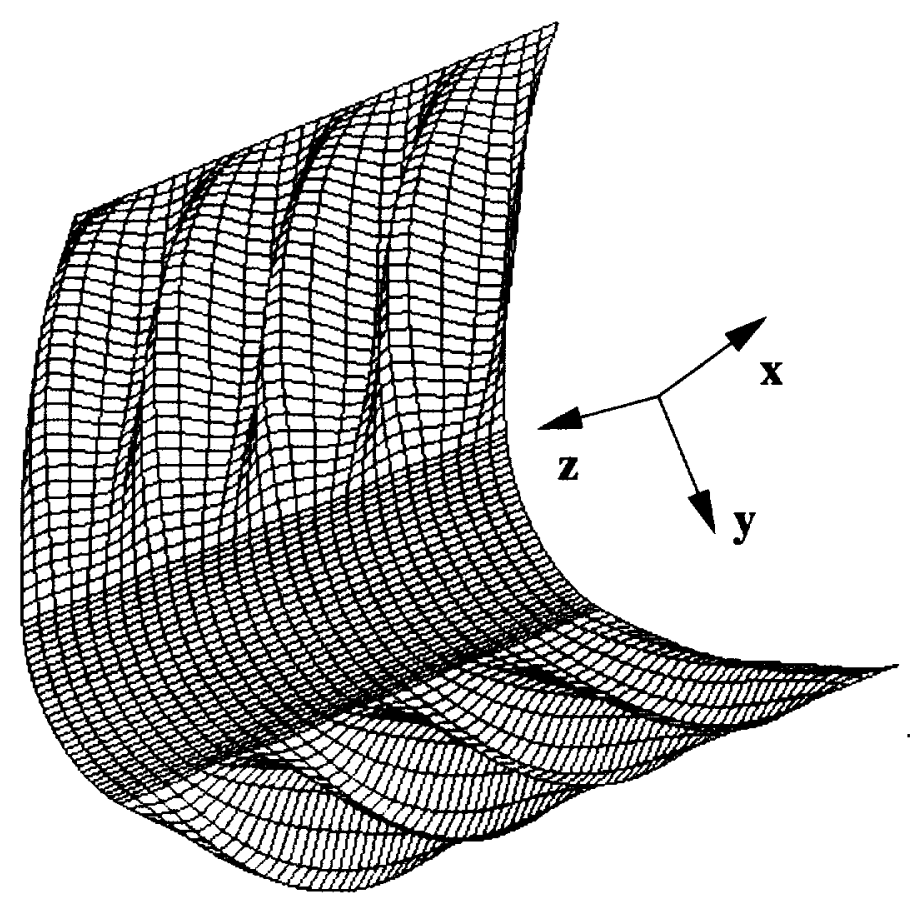

Figure 7: Buckling mode shape for the composite wing leading-edge panel in axial compression loading.

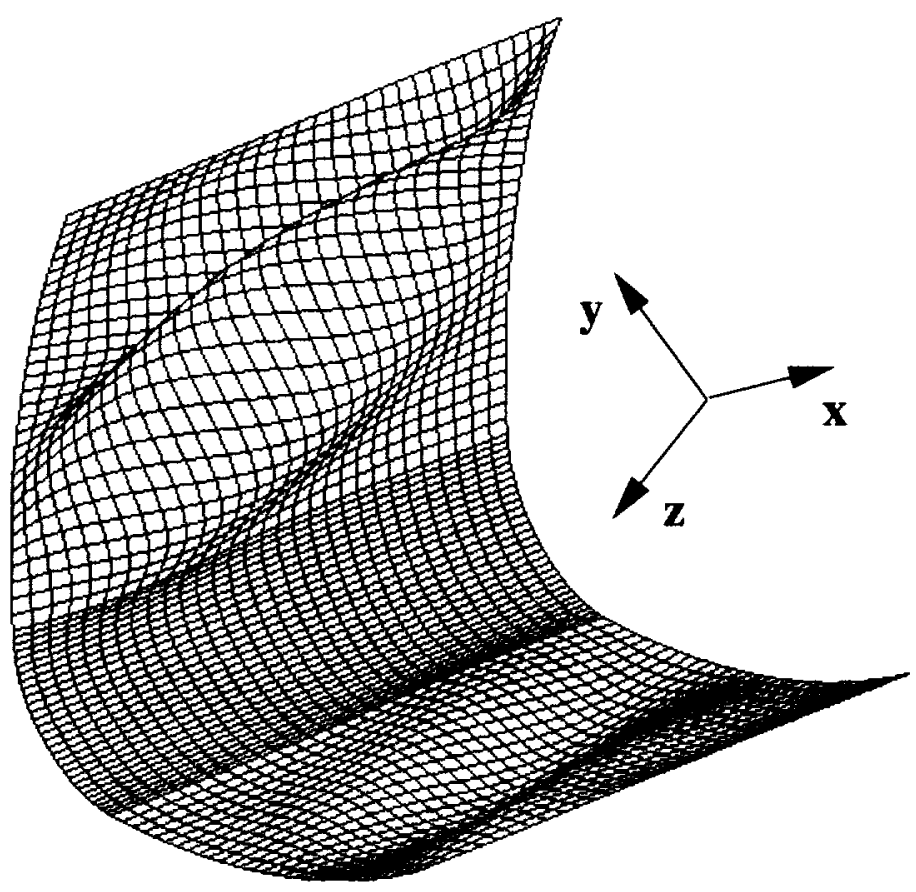

Figure 8: Buckling mode shape for the composite wing leading-edge panel in negative shear loading. 


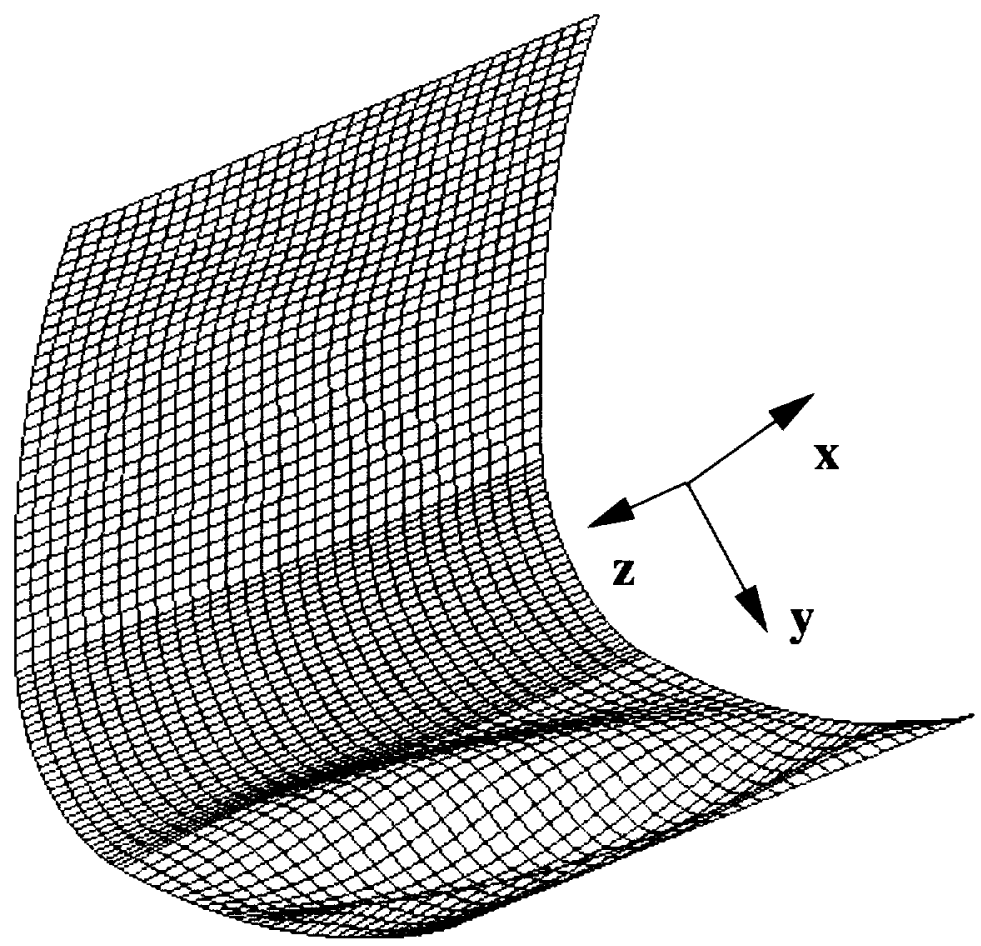

I'Enr. !! Burkling mode shape for the composite wing leadlug-edge panel in positive slear loading. 
